University of Nebraska - Lincoln

DigitalCommons@University of Nebraska - Lincoln

2008

Hierarchical Assemblies of Block-Copolymer-Based

Supramolecules in Thin Films

Shih-Huang Tung

Nisha C. Kalarickal

Jimmy W. Mays

Ting $\mathrm{Xu}$

Follow this and additional works at: https://digitalcommons.unl.edu/usdoepub

Part of the Bioresource and Agricultural Engineering Commons

Tung, Shih-Huang; Kalarickal, Nisha C.; Mays, Jimmy W.; and Xu, Ting, "Hierarchical Assemblies of BlockCopolymer-Based Supramolecules in Thin Films" (2008). US Department of Energy Publications. 76. https://digitalcommons.unl.edu/usdoepub/76

This Article is brought to you for free and open access by the U.S. Department of Energy at DigitalCommons@University of Nebraska - Lincoln. It has been accepted for inclusion in US Department of Energy Publications by an authorized administrator of DigitalCommons@University of Nebraska - Lincoln. 


\title{
Hierarchical Assemblies of Block-Copolymer-Based Supramolecules in Thin Films
}

\author{
Shih-Huang Tung, ${ }^{\dagger}$ Nisha C. Kalarickal, ${ }^{\dagger}$ Jimmy W. Mays," and Ting Xu ${ }^{*, \dagger, \ddagger, \S}$ \\ Department of Materials Science and Engineering and Department of Chemistry, University of \\ California, Berkeley, California 94720-1760; Material Sciences Division, Lawrence Berkeley National \\ Laboratory; and Chemical Sciences Division and Center for Nanophase Materials Sciences, Oak Ridge \\ National Laboratory, Oak Ridge, Tennessee 37831
}

Received April 1, 2008; Revised Manuscript Received June 25, 2008

\begin{abstract}
The hierarchical assemblies of supramolecules, which consisted of polystyrene- $b$-poly(4vinylpyridine) (PS- $b$-P4VP) with 3-pentadecylphenol (PDP) hydrogen-bonded to the 4VP, were investigated in thin films after solvent annealing in a chloroform atmosphere. The synergistic coassembly of PS- $b$-P4VP and PDP was utilized to generate oriented hierarchical structures in thin films. Hierarchical assemblies, including lamellae-within-lamellae and cylinders-within-lamellae, were simultaneously ordered and oriented from a few to several tens of nanometers over macroscopic length scales. The macroscopic orientation of supramolecular assembly depends on the P4VP(PDP) fraction and can be tailored by varying the PDP to P4VP ratio without interfering with the supramolecular morphologies. The lamellar and cylindrical microdomains, with a periodicity of $\sim 40 \mathrm{~nm}$, could be oriented normal to the surface, while the assembly of comb blocks, P4VP(PDP), with a periodicity of $\sim 4 \mathrm{~nm}$, were oriented parallel to the surface. Furthermore, using one PS- $b$-P4VP copolymer, thin films with different hierarchical structures, i.e., lamellae-withinlamellae and cylinders-within-lamellae, were obtained by varying the ratio of PDP to 4VP units. The concepts described in these studies can be potentially applied to other BCP-based supramolecular thin films, thus creating an avenue to functional, hierarchically ordered thin films.
\end{abstract}

\section{Introduction}

Significant progress has been made in controlling the microdomain orientation and long-range ordering in block copolymer (BCP) thin films. ${ }^{1-8}$ Achieving nanostructures with feature sizes below $10 \mathrm{~nm}$ is challenging, and most synthetic self-assembling systems have been restricted to planar (2D) structures. ${ }^{9}$ Reports on hierarchical structures in thin films are limited to several examples observed in multiblock copolymers. ${ }^{10}$ Integrating functionality into these assemblies has relied on postassembly chemical reactions or the synthesis of new copolymers. ${ }^{11}$ However, the self-assembly of supramolecules offers a route to overcome these impediments.

BCP-based supramolecules are prepared by attaching small molecules to the side chains of one of the BCP blocks. ${ }^{12-16}$ $\mathrm{BCP}$-based supramolecules microphase separate into arrays of microdomains, tens of nanometers in size, which is similar to that seen in linear BCPs. ${ }^{17,18}$ The small molecules in the BCPbased supramolecules, in turn, form molecular assemblies within one of the microdomains, resulting in hierarchical structures with built-in functionalities. ${ }^{19}$ Ikkala and ten Brinke developed a versatile methodology to construct BCP-based supramolecules by attaching small molecules to BCPs via hydrogen bonding, electrostatic interactions, and metal coordination and have demonstrated a rich library of hierarchical structures that can be obtained by their self-assembly in the bulk. These supramolecules offer advantages over the covalently linked analogues, since different functionalities can be incorporated into the assemblies simply by substituting the small molecules, thereby avoiding the need to synthesize entirely new families of BCPbased supramolecules. ${ }^{20,21}$ Tunable morphologies are readily accessible using a single BCP either by varying the stoichiometry between the small molecules and BCPs or by redistributing

\footnotetext{
* Corresponding author. E-mail: tingxu@berkeley.edu.

$\dagger$ Department of Materials Science and Engineering, UC Berkeley.

Department of Chemistry, UC Berkeley.

$\S$ Lawrence Berkeley National Laboratory.

"Oak Ridge National Laboratory.
}

(a)

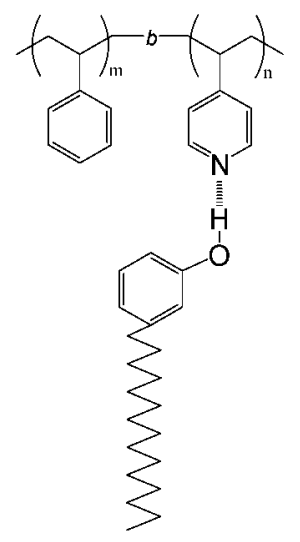

(b)
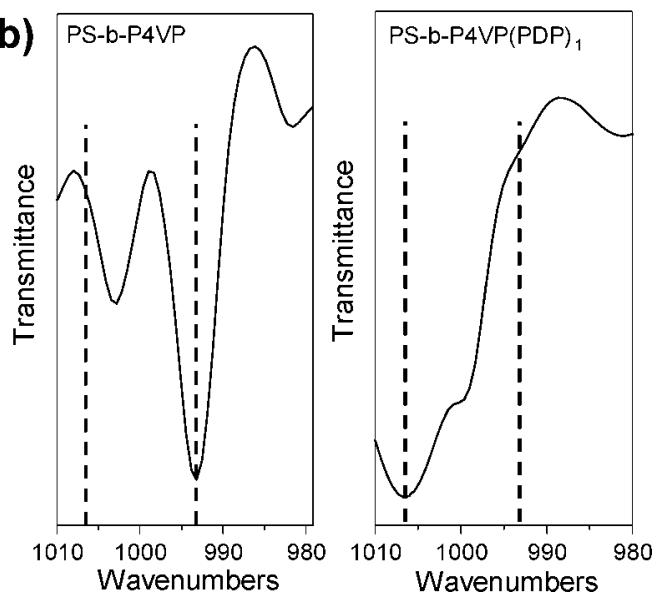

Figure 1. (a) Chemical drawing of the diblock copolymer-based supramolecule, PS- $b$-P4VP(PDP). (b) FT-IR spectra of thin films of PS- $b$-P4VP and PS- $b$-P4VP(PDP).

the small molecules between the two microdomains using an external stimulus, like heat. ${ }^{12}$ 


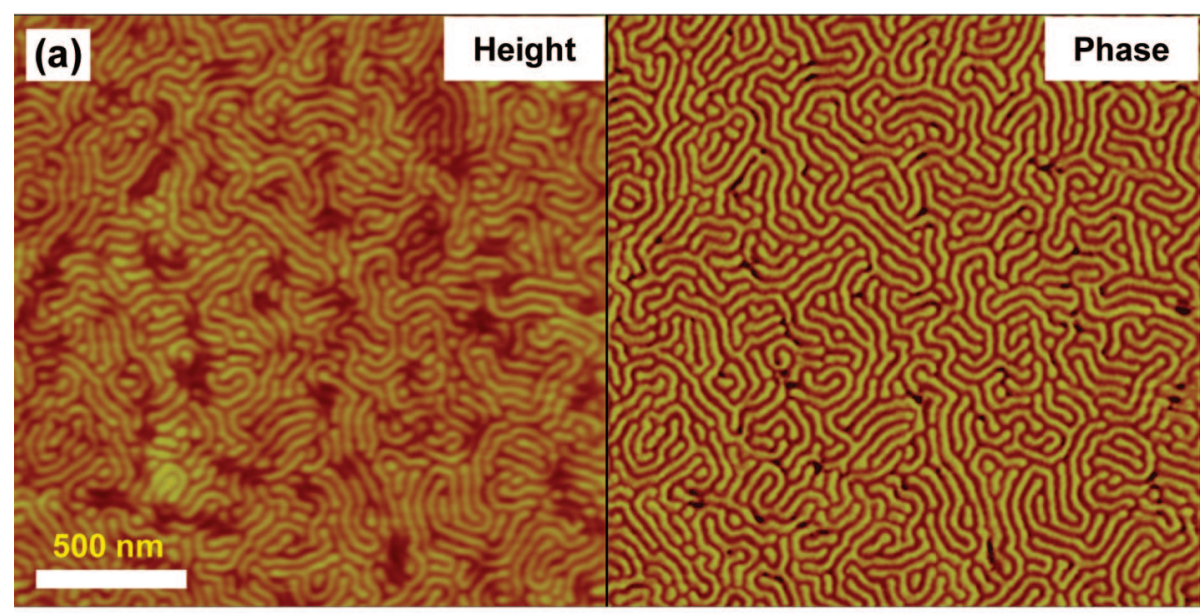

(b)

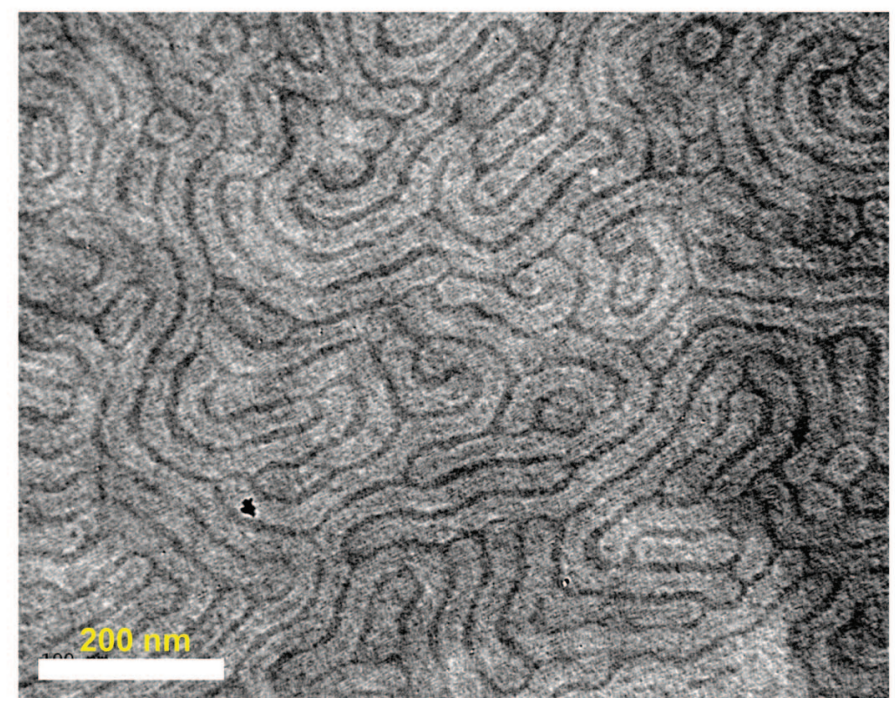

Figure 2. (a) SPM height and phase image of a SP1 thin film, $\sim 47 \mathrm{~nm}$ in thickness. The $z$ scale is $30 \mathrm{~nm}$ for height and $15^{\circ}$ for phase. (b) In-plane TEM image of a $\sim 50 \mathrm{~nm} \mathrm{SP1}$ thin film. The sample has been stained with $\mathrm{RuO}_{4}$.

Table 1. Characteristics of Samples ${ }^{a}$

\begin{tabular}{lcccccl}
\hline & & & & & \multicolumn{3}{c}{ morphology $\left(25{ }^{\circ} \mathrm{C}\right)$} \\
\cline { 5 - 7 } sample & $M_{\mathrm{n}, \mathrm{PS}}(\mathrm{g} / \mathrm{mol})$ & $M_{\mathrm{n}, \mathrm{P} 4 \mathrm{VP}}(\mathrm{g} / \mathrm{mol})$ & $R_{0}$ & $f_{\text {comb }}$ & bulk $^{b}$ & thin film \\
\hline SP1 & 31900 & 13200 & 1 & 0.62 & gyroid & lamella \\
SP2 & 20000 & 19000 & 1 & 0.79 & cylinder & cylinder \\
SP3-1 & 26200 & 12400 & 0.64 & 0.57 & lamella & lamella \\
SP3-2 & 26200 & 12400 & 1.27 & 0.69 & L + C & L + C \\
SP3-3 & 26200 & 12400 & 1.8 & 0.75 & cylinder & cylinder \\
SP4 & 40000 & 5600 & 1 & 0.35 & lamella & lamella \\
SP5-1 $^{c}$ & 42000 & 5100 & 1 & 0.32 & lamella & lamella \\
SP5-2 $^{c}$ & 42000 & 5100 & 2 & 0.45 & lamella & lamella \\
SP5-3 $^{c}$ & 42000 & 5100 & 2.5 & 0.50 & lamella & lamella
\end{tabular}

${ }^{a} R_{0}$ : molar ratio of PDP to P4VP; $f_{\text {comb }}$ : weight fraction of P4VP(PDP); L: lamella; C: cylinder. ${ }^{b}$ Bulk samples were annealed at $100^{\circ} \mathrm{C}$ in a nitrogen atmosphere for $48 \mathrm{~h} .{ }^{c}$ The polystyrene block is deuterated.

Thin films of BCP-based supramolecules, with controlled macroscopic orientation and lateral order, afford a viable route to hierarchical structures and the fabrication of functional devices. The macroscopic alignment of BCP microdomains using well-developed procedures, along with the unique characteristics of the small molecule, further enable the tailoring of the orientation and ordering of the BCP-based supramolecules over multiple length scales. ${ }^{22,23}$ For example, the small molecule can be used to tailor the surface tension or interfacial interactions with a substrate so as to manipulate the orientation of the microdomains. ${ }^{24}$ In addition, the ordering or self-assembly of the small molecule can modify the chain configuration of the parent BCP, providing further control over the supramolecular assembly. ${ }^{25}$

To date, most studies on the BCP-based supramolecules have focused on the phase behavior in the bulk with a limited number of reports on their thin-film behavior. These studies have focused primarily on controlling the BCP microdomain orientation. ${ }^{23,26,27}$ Minko et al. have fabricated well-ordered, nanostructured thin films from the supramolecular assemblies of poly(styrene)- $b$ poly(4-vinylpyridine) (PS- $b$-P4VP) and 2-(4'-hydroxybenzeneazo)benzoic acid (HABA), consisting of cylindrical microdomains formed by P4VP(HABA) surrounded by PS. The orientation of the microdomains in thin films could be switched by exposure to different solvent vapors. Recently, ten Brinke et al. examined the phase behavior and terrace formation of supramolecular thin films annealed under different chloroform vapor pressures. The supramolecules were constructed by hydrogen-bonding 3-pentadecylphenol (PDP) to the 4VP moieties of a PS- $b$-P4VP. The weight fractions of P4VP(PDP) complexes were below 0.4 , in the regime where P4VP(PDP) blocks form cylindrical or lamellar microdomains. It was observed that the P4VP(PDP) was present at the $\mathrm{SiO}_{2}$ interface as well as the air interface, implying symmetric boundary conditions, and the morphologies depended on the chloroform vapor pressure as well as on the formation of terraces. ${ }^{33}$ However, there have been limited reports on controlling the supramolecular assemblies over multiple length scales, in particular the assembly of small molecules within the microdomains, thereby achieving hierarchically ordered structures. 
(a) $\alpha_{\text {in }}=0.2^{\circ}$

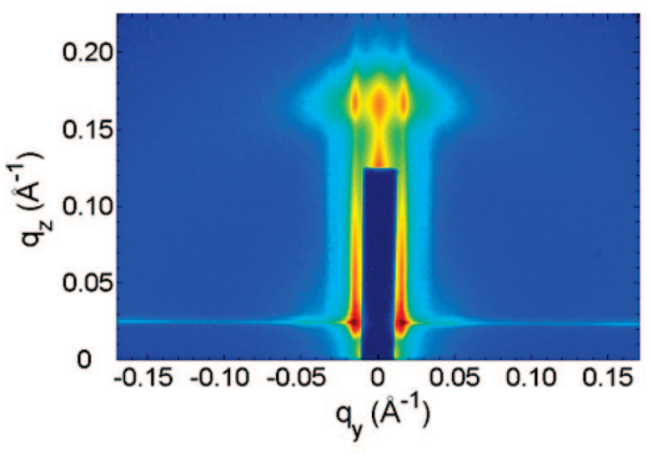

(c)

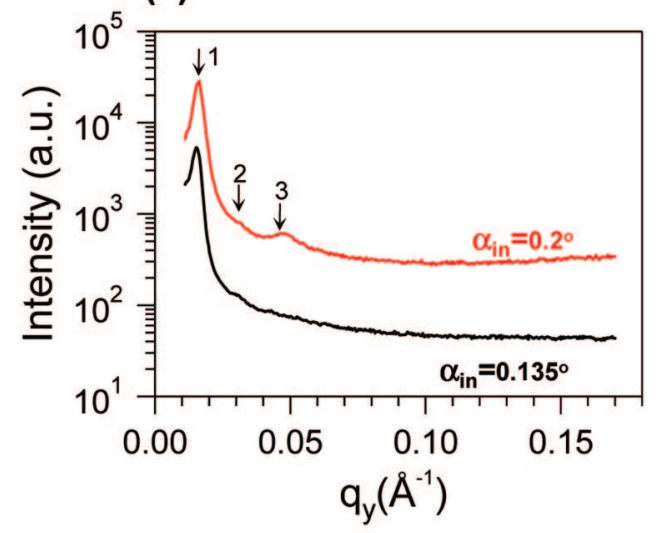

(b) $\alpha_{\text {in }}=0.135^{\circ}$

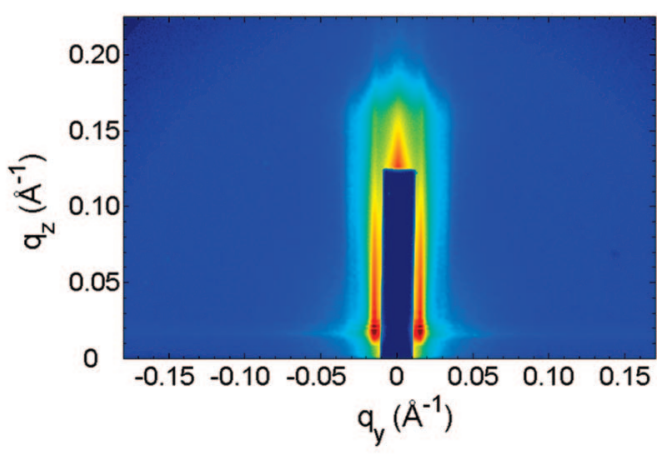

(d)

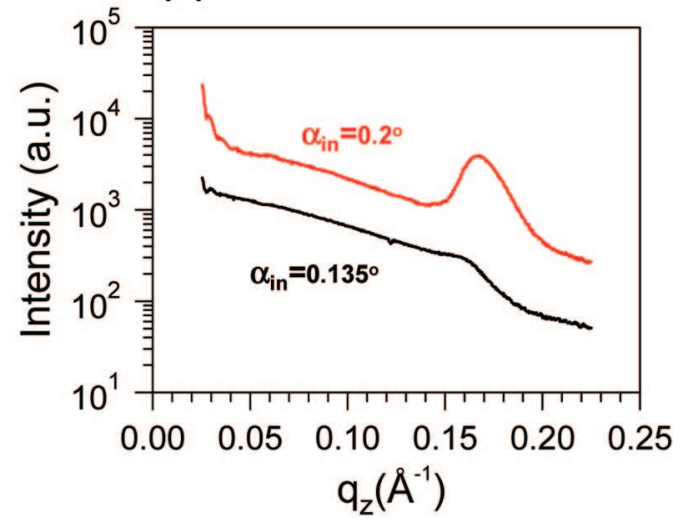

(e)

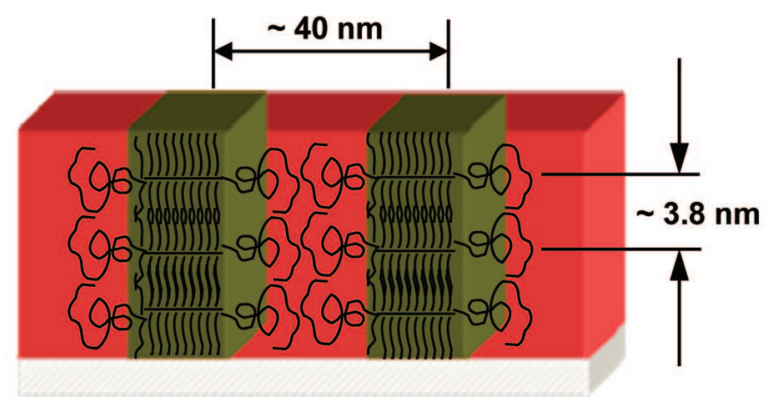

Figure 3. GISAXS patterns of a $\sim 47 \mathrm{~nm} \mathrm{SP} 1$ thin film at an incident angle of (a) $0.135^{\circ}$ and (b) $0.2^{\circ}$. (c) The $q_{y}$ scans at $q_{\mathrm{z}}=0.020 \AA^{-1}$ for $\alpha_{\text {in }}$ $=0.135^{\circ}$ and $0.024 \AA^{-1}$ for $\alpha_{\text {in }}=0.2^{\circ}$, showing the lamellar microdomains with a $39.3 \mathrm{~nm}$ periodicity are oriented perpendicular to the surface throughout the film. (d) The $q_{\mathrm{z}}$ scans at $q_{y}=0.015 \AA^{-1}$, showing the P4VP(PDP) lamellae with a 3.8 nm periodicity, are oriented parallel to the surface. Both scans are extracted from the right side of the GISAXS patterns. (e) Schematic drawing of the lamellae-within-lamellar hierarchical structure in SP1 thin films.

Moeller et al. investigated the thin film morphologies of wedgeshaped liquid crystalline amphiphilic molecules complexed with poly(2-vinylpyridine)- $b$-poly(ethylene oxide) (P2VP- $b$-PEO) diblock copolymer via proton transfer. ${ }^{28}$ The complex microphase separated with parallel smectic layers of the complexed P2VP blocks throughout the thin films. By varying the degree of neutralization, namely the stoichiometry of the wedge-shaped molecule to 2VP, the block copolymer thin film structures can be controlled. The small molecules in this case are liquid crystalline, and their assembly can dominate the assembly of the supramolecules. ${ }^{29-32}$

In our studies, the hierarchical assembly of BCP-based supramolecules in thin films on different length scales, i.e., from several to tens of nanometers, over macroscopic distances was investigated using the PS- $b$-P4VP(PDP) supramolecular systems similar to those reported by ten Brinke et al. ${ }^{13,33,34}$ Systematic studies were carried out using PS- $b$-P4VP(PDP) supramolecules with a wide range of $\mathrm{P} 4 \mathrm{VP}(\mathrm{PDP})$ weight fraction, i.e., from 0.32 to 0.79 . After solvent annealing under a chloroform atmosphere, hierarchical assemblies, e.g., lamellae-within- lamellae and cylinders-within-lamellae, were oriented over macroscopic distances in thin films. Macroscopically oriented hierarchical structures were achieved on two length scales simultaneously. There is a strong correlation between the orientation of supramolecular assembly in thin films and the weight faction of P4VP(PDP). Above a critical weight fraction of P4VP(PDP), $\sim 0.45$, the BCP microdomains, $\sim 40 \mathrm{~nm}$ in size, were oriented normal to the surface with the layered comb structures of $\mathrm{P} 4 \mathrm{VP}(\mathrm{PDP})$ blocks, $\sim 4 \mathrm{~nm}$, oriented parallel to the surface. At a low fraction of P4VP(PDP), 0.35 , the BCP lamellar microdomains were oriented parallel to the surface. Within the microdomains, the P4VP(PDP) lamellae were oriented perpendicular to the surface. This macroscopic orientation transition was achieved by either using BCPs with high fraction of P4VP blocks or increasing the PDP to $4 \mathrm{VP}$ stoichiometric ratio. In addition, using one PS- $b$-P4VP copolymer, thin films with different hierarchical structures, i.e., lamellae-within-lamellae and cylinders-within-lamellae, were obtained by varying the ratio of $4 \mathrm{VP}$ units to PDP. In the case of cylinder-within-lamellae where P4VP(PDP) blocks form 


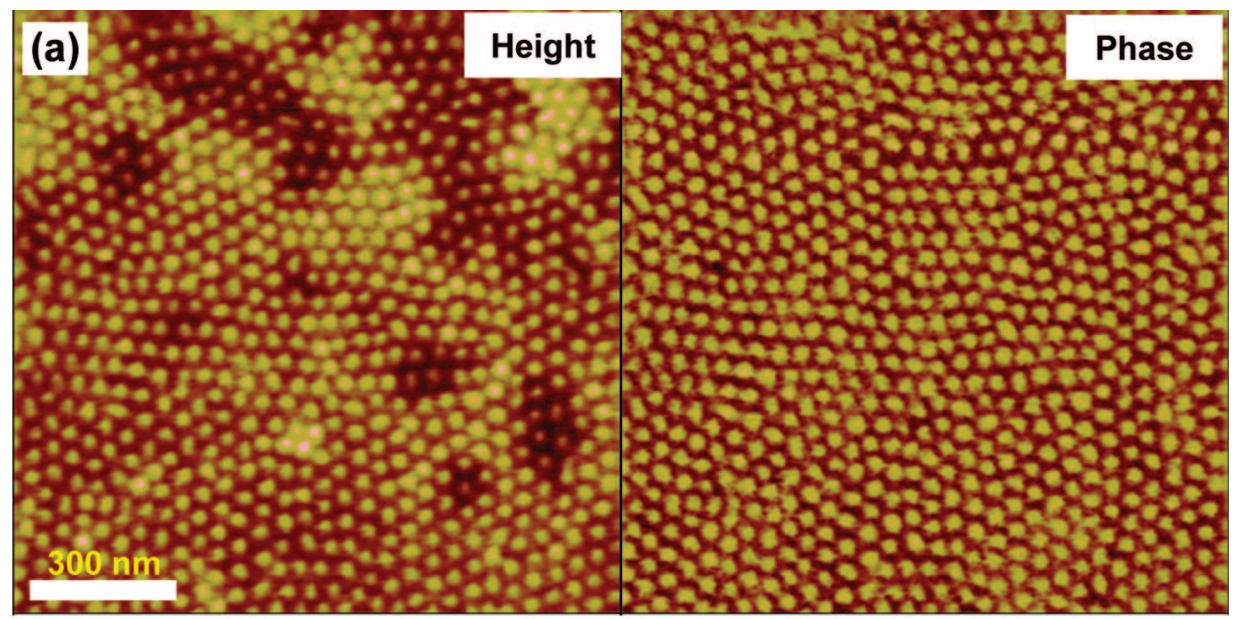

(b)

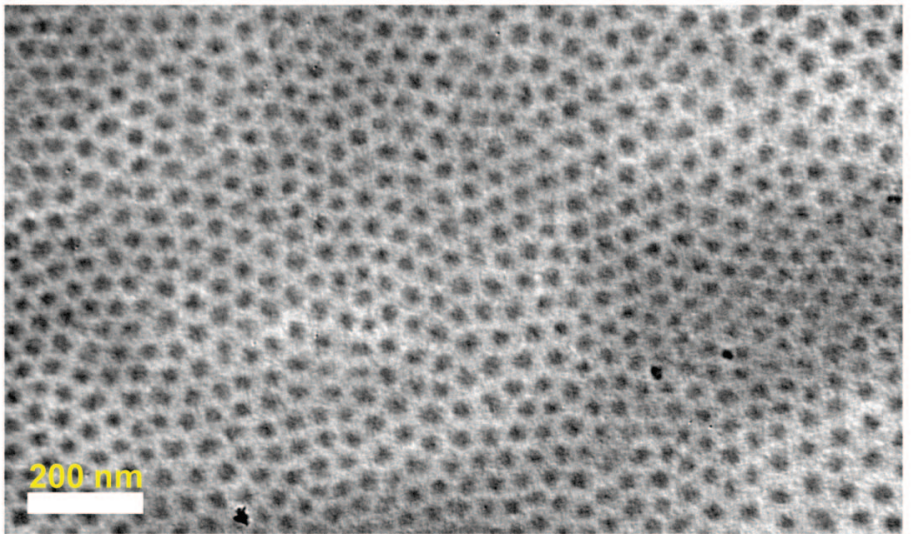

Figure 4. (a) SPM height and phase image of a SP2 thin film, $\sim 50 \mathrm{~nm}$ in thickness. The $z$ scale is $10 \mathrm{~nm}$ for height and $20^{\circ}$ for phase. (b) TEM image of a $\sim 50 \mathrm{~nm} \mathrm{SP} 2$ thin film. The sample has been stained with $\mathrm{RuO}_{4}$.

matrix, thin films with PS-rich cylindrical microdomains oriented normal to the surface were obtained over a large range of film thicknesses.

\section{Experimental Section}

Materials. PS(26200)- $b$-P4VP(12400) (PDI $=1.08)$ was synthesized in-house using anionic polymerization process. Details on the synthesis and the GPC and NMR spectra are shown in the Supporting Information. Deuterated-polystyrene-based diblock copolymer dPS(42000)- $b$-P4VP(5100) was provided by the Center for Nanophase Materials Sciences (CNMS) at Oak Ridge National Laboratory (ORNL). Other diblock copolymers, i.e. PS(31900)- $b$ P4VP(13200) (PDI = 1.08), PS(20000)- $b$-P4VP(19000) $(\mathrm{PDI}=$ 1.09), and PS(40000)- $b$-P4VP(5600) (PDI $=1.09)$ were purchased from Polymer Source, Inc. 3-n-Pentadecylphenol (95\%) was purchased from Acros. Chloroform was purchased from Fisher. All chemicals were used as received.

Sample Preparation. The characteristics of all samples used in this paper are listed in Table 1 . The diblock copolymer, PS- $b$-P4VP, was first dissolved in chloroform to form $1 \%-2 \%$ (w/v) stock solutions. The desired amount of PDP was dissolved in chloroform. The PS- $b$-P4VP solution was then added dropwise to the PDP solution, followed by stirring overnight. Thin films were prepared by spin-coating the mixed solutions onto silicon wafers at spinning speeds between 1000 and $3000 \mathrm{rpm}$. Sample thicknesses were measured using a Filmetrics F20 interferometer. For solvent annealing, thin films were placed together with a beaker of $40 \mathrm{~mL}$ of chloroform at $22{ }^{\circ} \mathrm{C}$ inside an inverted dish $(170$ diameter $\times 90$ $\mathrm{H} \mathrm{mm}$ ) on which a weight $\sim 2 \mathrm{~kg}$ was loaded. The swelling ratios, i.e., the thickness ratio of swollen films to original films, are between 1.5 and 2 at the chloroform vapor pressure using this setup, which was determined from the color changes of the films during annealing. No terrace was observed under the optical microscope $(\mathrm{OM})$ after solvent annealing using this setup. The OM images taken before and after solvent annealing are provided in the Supporting Information.

FT-IR. The FT-IR sample was prepared by dropping a $100 \mu \mathrm{L}$ chloroform solution onto a $\mathrm{KBr}$ plate and allowing the film to airdry. IR spectra were recorded in transmission with a Bruker spectrometer model Vector 33.

SAXS. For SAXS experiments, the PS- $b$-P4VP(PDP) solutions were slowly dried in a Teflon beaker (typically $5 \mathrm{~mL}$ over 2 days). The samples were then thermally annealed at $100{ }^{\circ} \mathrm{C}$ under nitrogen for $48 \mathrm{~h}$. The SAXS data were collected on beamline 7.3.3 in the Advanced Light Source (ALS) at the Lawrence Berkeley National Laboratory. X-rays, with a wavelength of $1.240 \AA$ (10 keV), were used, and the scattering spectra were corrected on an ADSC Quantum 4u CCD detector with an active area of $188 \mathrm{~mm}$ by 188 $\mathrm{mm}$ (2304 by 2304 pixels) and a dynamic range of 16 bit. The scattering profiles, after a $20 \mathrm{~s}$ collection time, were obtained by integrating the 2-D scattering pattern. Scattering profiles are shown in the Supporting Information.

GISAXS. Grazing incidence small-angle X-ray scattering (GISAXS) measurements were made on beamline 8-ID-E in the Advanced Photo Source (APS) at the Argonne National Laboratory and on beamline 7.3 in ALS. X-ray wavelengths of 1.687 and 1.240 $\AA$ were used. The scattering profiles were collected on a Mar-CCD at APS and an ADSC Quantum $4 \mathrm{u}$ CCD detector at ALS. Lineaveraged intensities are reported as $I$ vs $q$, where $q=(4 \pi / \lambda) \sin (\theta /$ $2), \lambda$ is the wavelength of incident $X$-rays, and $\theta$ is the scattering angle.

SPM. Scanning probe microscopy (SPM) was performed either on a Digital Instruments BioScope with a Nanoscope IIIa controller or on a Molecular Imaging PicoSPM II with a PicoScan 2500 
(a)

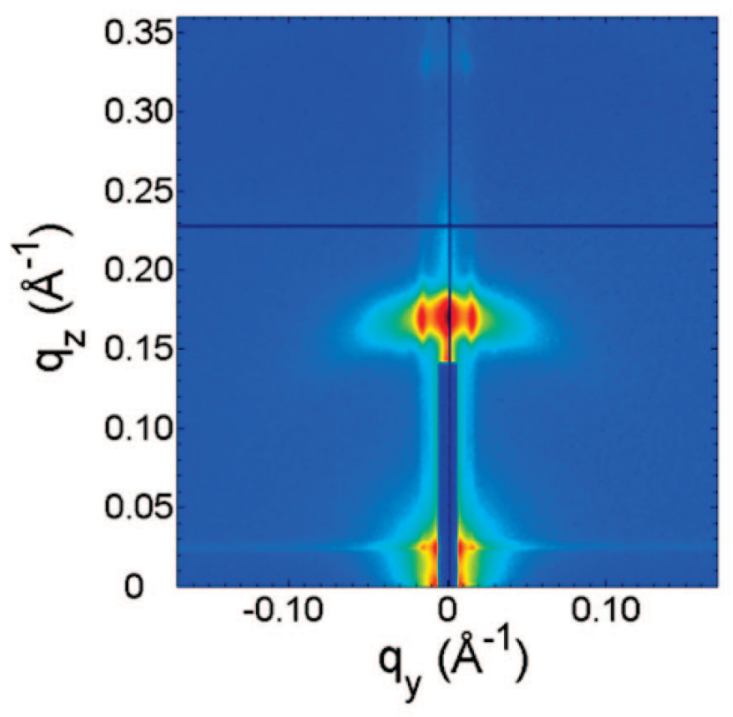

(b)

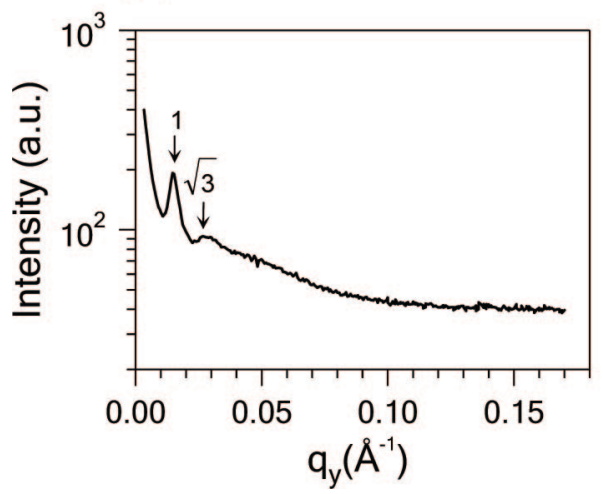

(c)

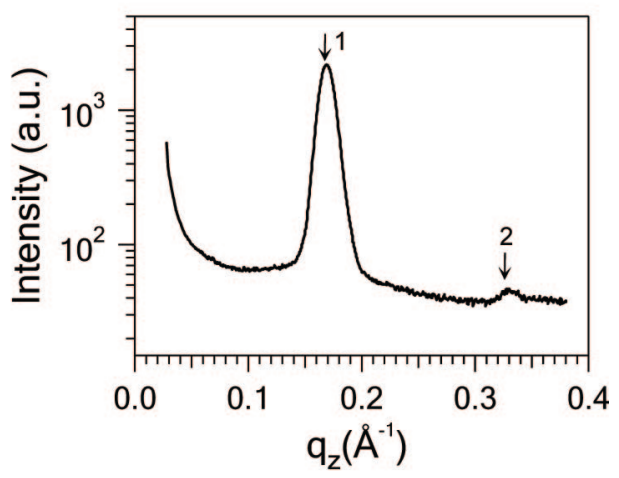

Figure 5. (a) GISAXS pattern of a $\sim 50 \mathrm{~nm} \mathrm{SP} 2$ thin film at an incident angle of $0.2^{\circ}$. (b) The $q_{y}$ scan at $q_{\mathrm{z}}=0.152 \AA^{-1}$, showing the PS-rich cylindrical microdomains, $41.3 \mathrm{~nm}$ in period, are oriented perpendicular to the surface. (c) The $q_{z}$ scan at $q_{y}=0.015 \AA^{-1}$, showing the P4VP(PDP) lamellae, $3.7 \mathrm{~nm}$ in period, are oriented parallel to the surface. Both scans are extracted from the right side of the GISAXS pattern.

controller using silicon cantilevers (RTESP from Veeco, Inc.). The spring constant of the cantilever was $20-80 \mathrm{~N} / \mathrm{m}$ with a resonant frequency in the range $304-349 \mathrm{kHz}$. SPM images were collected on the same samples used in the GISAXS experiments. The set point for autotune was $2.5 \mathrm{~V}$. The set-point amplitude was $90 \%$ of the free vibration value. The driving amplitudes were typically adjusted to $\sim 50 \%$ higher than the autotuned values to obtain images with better clarity.

Transmission Electron Microscope. For TEM studies, PS- $b$ $\mathrm{P} 4 \mathrm{VP}(\mathrm{PDP})$ thin films were coated on sodium chloride $(\mathrm{NaCl})$ disks in a manner similar to those on silicon substrates. After solvent annealing, films were floated off the substrate onto a pool of water. Thin films were retrieved with copper grids and stained by exposing to ruthenium tetraoxide $\left(\mathrm{RuO}_{4}\right)$ vapor for $30 \mathrm{~min}$ to enhance the contrast. TEM images were collected on a FEI Tecnai 12 transmission electron microscope at an accelerating voltage of $100 \mathrm{kV}$.

\section{Results and Discussion}

PS- $b$-P4VP(PDP) supramolecules are prepared by hydrogen bonding 3-pentadecylphenol (PDP) to the 4VP, as previously shown by Ikkala and ten Brinke. ${ }^{13,34}$ The chemical structure of the coil-comb PS- $b$-P4VP(PDP) supramolecule is shown in Figure 1a. Figure 1b shows the FT-IR spectra of a PS- $b$-P4VP thin film and a PS- $b$-P4VP(PDP) thin film. Free pyridine groups in the PS- $b$-P4VP thin film contribute to the absorption at 993 $\mathrm{cm}^{-1}$. The hydrogen-bonded pyridine groups have absorption at $1005-1010 \mathrm{~cm}^{-1}$. As seen upon hydrogen bonding to the PDP, the absorption at $993 \mathrm{~cm}^{-1}$ disappeared, and the integrity of the supramolecule, PS- $b$-P4VP(PDP), in thin films was confirmed. ${ }^{13,34}$

Table 1 lists five families of PS- $b$-P4VP(PDP) supramolecules used and their morphologies in the bulk. SP1 is based on PS(31900)- $b$-P4VP(13200) and forms a gyroid morphology. SP2 is based on PS(20000)- $b$-P4VP(19000) and forms hexagonally packed PS-rich cylindrical microdomains embedded in a P4VP(PDP) matrix. SP3-1, SP3-2, and SP3-3 were prepared using PS(26200)- $b$-P4VP(12400) with ratios of PDP to P4VP $\left(R_{0}\right)$ of $0.67,1$ and 1.8 , respectively. In the bulk, SP3-1 forms lamellae-within-lamellae, SP3-3 forms cylinders-within-lamellae, and SP3-2 shows a mixture of both morphologies. SP4 is based on PS(40000)- $b$-P4VP(5600) and forms lamellae-withinlamellae in the bulk. SP5-1, SP5-2, and SP5-3 were prepared by dPS(42000)- $b$-P4VP(5100) with $R_{0}=1,2$, and 2.5 , respectively. The usage of the deuterated block copolymer was for the ongoing neutron reflectivity studies. Those three samples form lamellae-within-lamellae structures in bulk.

Thermal annealing and solvent annealing under a chloroform atmosphere were investigated to obtain nanostructures in the thin films of PS- $b$-P4VP(PDP). PDP was found to evaporate with annealing at $100{ }^{\circ} \mathrm{C}$ under vacuum or nitrogen, resulting in a $\sim 30 \%$ or more loss in film thickness. Thus, solvent annealing was used to self-assemble PS- $b$-P4VP(PDP) in thin films. The ratios of PDP to $4 \mathrm{VP}$ listed in Table 1 are those used experimentally. The PDP selectively hydrogen bonds to the 4VP. However, trace amounts of PDP are soluble in the PS 

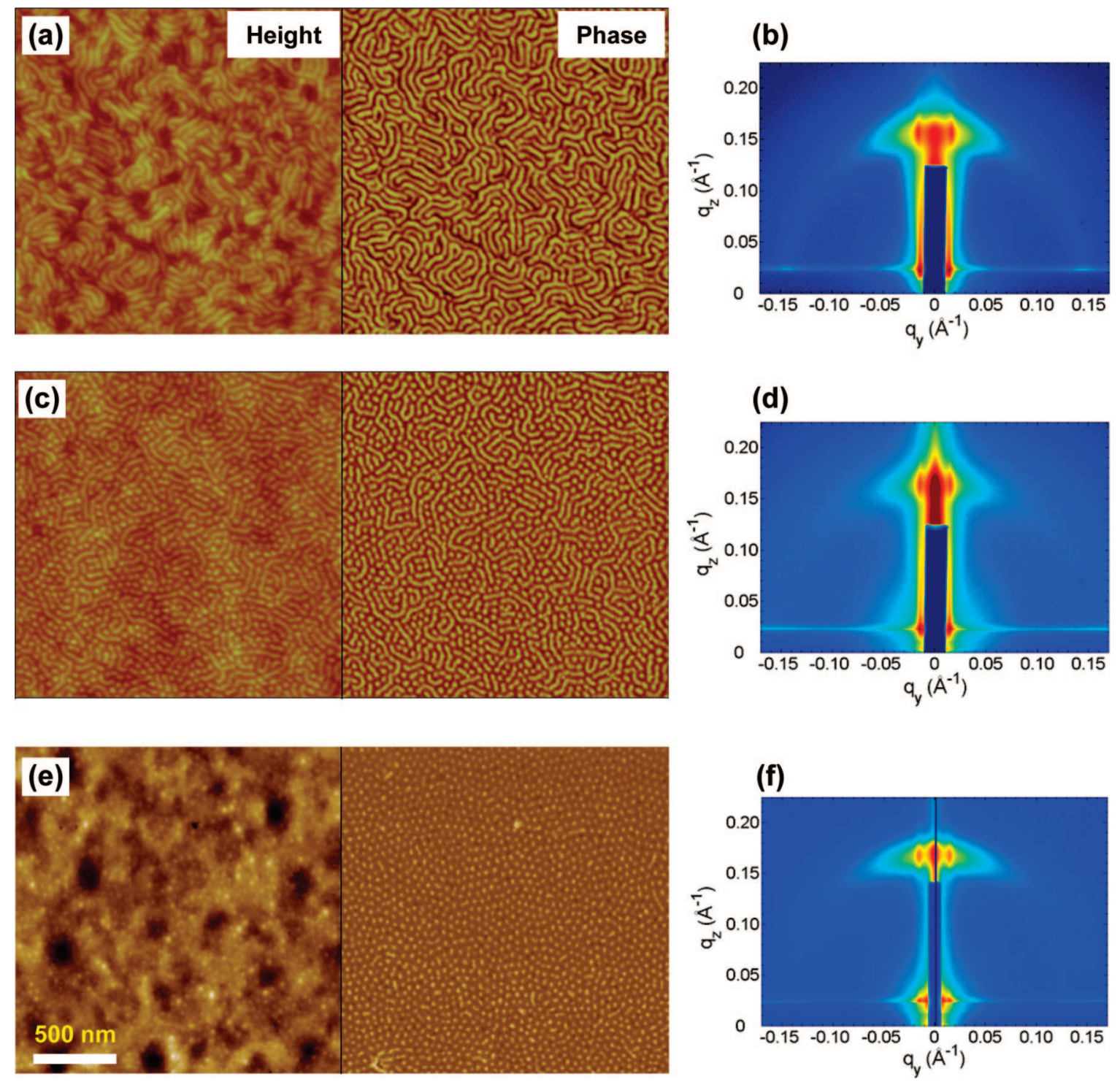

Figure 6. Morphology evolution of PS- $b$-P4VP(PDP) by varying the stoichiometry of PDP to P4VP. SPM height and phase images and GISAXS patterns of (a) and (b): a $\sim 72 \mathrm{~nm}$ SP3-1 thin film, showing a lamellae-within-lamellae morphology; (c) and (d): a $\sim 48 \mathrm{~nm}$ SP3-2 thin film, showing a mixed morphology of lamellae-within-lamellae and cylinder-within-lamellae; (e) and (f): a $55 \mathrm{~nm}$ SP3-3 thin film, showing a cylinder-withinlamellae morphology. The $z$ scale for height and phase is $40 \mathrm{~nm}$ and $50^{\circ}$ for (a), $20 \mathrm{~nm}$ and $25^{\circ}$ for (c), and $20 \mathrm{~nm}$ and $70^{\circ}$ for (e).

domain and can be redistributed between two microdomains via external stimuli. ${ }^{14}$ Chloroform mediates the interactions between the PS and PDP and may further enhance the PDP solubility in PS. The exact partitioning of the PDP in the PS and P4VP microdomains is not known at present and is currently being studied.

None of the PS- $b$-P4VP copolymers formed ordered structures in thin films after solvent annealing for $48 \mathrm{~h}$, as seen by the SPM and GISAXS (data not shown). This is due to the low mobility of PS and P4VP blocks. However, PDP significantly increases the mobilities of both blocks and ordered structures of PS- $b$-P4VP(PDP) supramolecules were observed after solvent annealing. Figure $2 \mathrm{a}$ shows SPM images of a $\sim 47 \mathrm{~nm} \mathrm{SP1}$ thin film after annealing in chloroform for $48 \mathrm{~h}$. A fingerprint-like pattern, with a domain spacing of $\sim 40 \mathrm{~nm}$, is seen. Similar patterns were observed in the in-plane TEM image shown in Figure 2b. Although the samples for SPM and TEM studies were prepared on two different substrates, i.e., silicon wafers and $\mathrm{NaCl}$ plates, differences in morphologies were not evident. We also floated the supramolecular thin films off the $\mathrm{NaCl}$ substrate. Upon imaging the bottom of the films, we observed SPM images similar to Figure 2a. (The SPM image can be found in the Supporting Information.) In the bulk, SP1 forms gyroidal morphology. The observed fingerprint-like pattern in Figure 2 indicates that the lamellar microdomains are oriented normal to the surface. This may be due to the preferrential swelling of the PS domain by chloroform or the solubilization of the PDP in the PS domain, both of which increase the PS volume fraction.

Parts a and $b$ of Figure 3 show the 2D GISAXS patterns of a SP1 thin film (the same sample used to obtain the SPM image in Figure 2a) at incidence angles $\left(\alpha_{\text {in }}\right)$ of $0.135^{\circ}$ and $0.2^{\circ}$, respectively. The critical angle $\left(\alpha_{\mathrm{c}, \mathrm{s}}\right)$ of the supramolecular thin film was $0.185^{\circ}\left(q_{\mathrm{c}, \mathrm{s}}=0.024 \AA^{-1}\right)$, measured by X-ray reflectivity. At $\alpha_{\text {in }}=0.135^{\circ}\left(q_{\text {in }}=0.018 \AA^{-1}\right)$, X-rays only probe the top $\sim 5-8 \mathrm{~nm}$ of the film. ${ }^{35}$ At $\alpha_{\text {in }}=0.2^{\circ}\left(q_{\text {in }}=\right.$ $0.026 \AA^{-1}$ ), the incident angle is slightly above $\alpha_{c, s}$ and X-rays penetrate the whole film, probing structural information throughout the film. For both GISAXS patterns, distinctive features at both $q_{z}$ and $q_{y}$ directions are seen. The $q_{y}$ scans at $q_{z}=0.020$ $\AA^{-1}$ for $\alpha_{\text {in }}=0.135^{\circ}$ and $0.024 \AA^{-1}$ for $\alpha_{\text {in }}=0.2^{\circ}$ are plotted in Figure $3 \mathrm{c}$. The relative position of the second- and thirdorder peaks to the first-order peak, 1:2:3, is characteristic of a lamellar microdomain morphology. The first-order peak at $q_{y}$ $=0.0160 \AA^{-1}$ corresponds to a spacing of $39.3 \mathrm{~nm}$, which is 


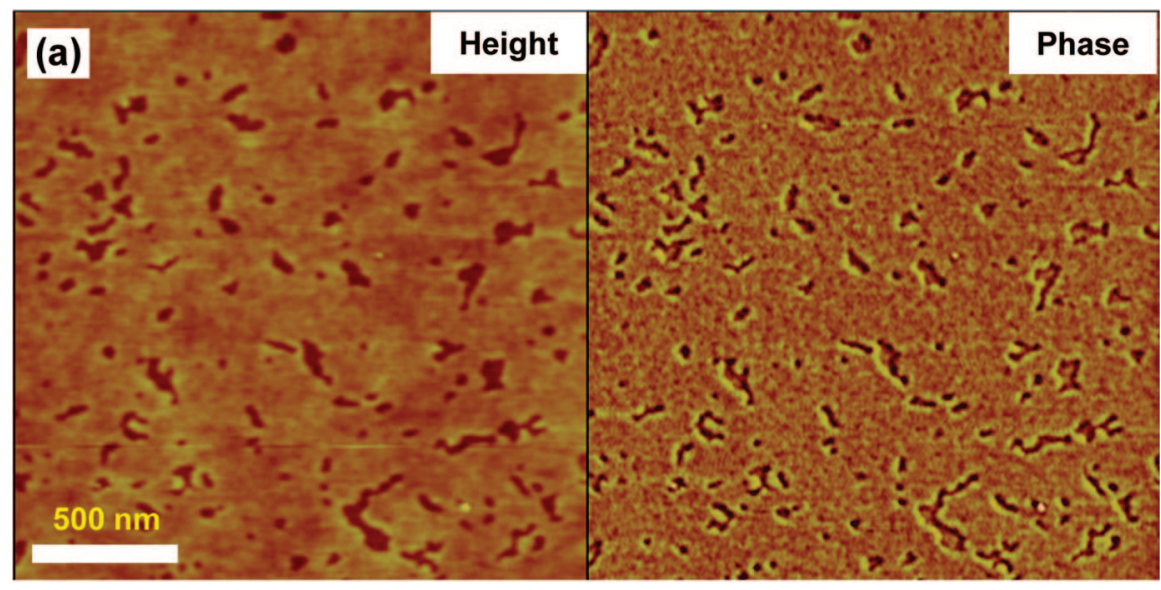

(b)

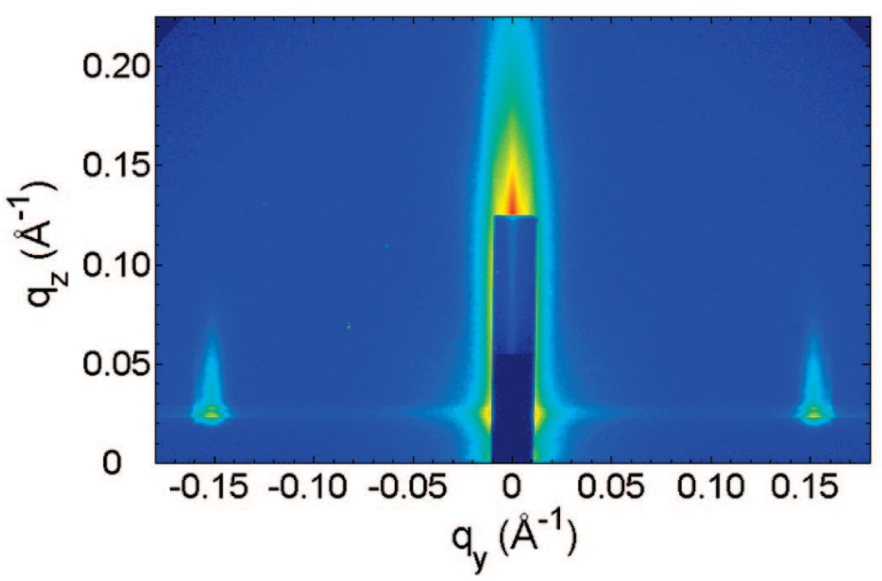

Figure 7. (a) SPM height and phase image of a SP4 thin film, $\sim 93 \mathrm{~nm}$ in thickness. The $z$ scale is $10 \mathrm{~nm}$ for height and $30^{\circ}$ for phase. (b) GISAXS pattern of a $\sim 93 \mathrm{~nm} \mathrm{SP} 4$ thin film at an incident angle of $0.2^{\circ}$.

consistent with the SPM and TEM results. The $q_{y}$ scans at $\alpha_{\text {in }}$ $=0.135^{\circ}$ and $\alpha_{\text {in }}=0.2^{\circ}$, as shown in Figure $3 \mathrm{c}$, are similar, indicating that the orientation of the lamellar microdomains penetrate through the entire film. A series of reflections at $q_{z} \sim$ $0.16 \AA^{-1}$ can also be seen, indicating a periodic structure parallel to the substrate. The $q_{\mathrm{z}}$ scan at $q_{y}=0.015 \AA^{-1}$, plotted in Figure $3 \mathrm{~d}$, shows a peak at $q_{\mathrm{z}}=0.166 \AA^{-1}$, corresponding to a much smaller structure with a periodicity of $\sim 3.8 \mathrm{~nm}$. This corresponds to a lamellar structure formed by the ordering of the alkyl tails of the PDP conjugated to the P4VP.

From the combined SPM, TEM, and GISAXS results, we can conclude that the morphology of the SP1 thin films is a lamellae-within-lamellae hierarchical assembly, as shown schematically in Figure 3e. The lamellar microdomains, $39.3 \mathrm{~nm}$ in size, originating from the $\mathrm{BCP}$ microphase separation are oriented normal to the substrate, while the smaller lamellar structure, $3.8 \mathrm{~nm}$ in size, formed by the assembly of the P4VP(PDP) comb blocks, are oriented parallel to the substrate, i.e., orthogonal to the BCP lamellar microdomains. SP1 thin films with thicknesses ranging from 40 to $150 \mathrm{~nm}$ have been studied, and the fingerprint-like surface topography was observed for all samples. GISAXS studies further confirmed that the BCP lamellar microdomains were perpendicular to the surface. However, the degree of orientation of the P4VP(PDP) lamellae reduced significantly as the film thickness increased.

Figure 4a show a SPM phase image of a $\sim 50 \mathrm{~nm} \mathrm{SP2}$ thin film after annealing in a chloroform atmosphere for $48 \mathrm{~h}$. The SPM phase image shows hexagonally packed circular domains with an interdomain spacing of $\sim 42 \mathrm{~nm}$. Figure $4 \mathrm{~b}$ shows a TEM image of a $\sim 50 \mathrm{~nm} \mathrm{SP} 2$ thin film prepared on a $\mathrm{NaCl}$ substrate. The film was exposed to $\mathrm{RuO}_{4}$ vapors that selectively stained the PS-rich block. Hexagonally packed PS-rich micro- domains are evident. Upon imaging the bottom of the films, we observed SPM images similar to Figure 4a. (The SPM image can be found in the Supporting Information.) SP2 forms a cylinders-within-lamellae structure in the bulk with the cylindrical PS-rich microdomains embedded in the P4VP/PDP matrix. GISAXS studies showed that SP2 forms cylinders, as in the bulk, oriented normal to the film surface. Figure 5a shows a GISAXS pattern of a $\sim 50 \mathrm{~nm} \mathrm{SP2}$ thin film after solvent annealing for $48 \mathrm{~h}$. The incident angle is $0.2^{\circ}$. Similar to SP1, peaks only appear along $q_{y}$ and $q_{z}$ axes. Bragg rods are clearly seen, demonstrating that SP2 forms hexagonally packed cylindrical microdomain oriented normal to the surface. The $q_{y}$ scan at $q_{\mathrm{z}}=0.152 \AA^{-1}$, plotted in Figure 5b, shows the first-order peak at $q=0.0152 \AA^{-1}$, corresponding to a periodicity of 41.3 $\mathrm{nm}$. The $q_{z}$ scan at $q_{y}=0.015 \AA^{-1}$, plotted in Figure $5 \mathrm{c}$, shows reflections at $q_{z}=0.169$ and $0.330 \AA^{-1}$, corresponding to a periodicity of $\sim 3.7 \mathrm{~nm}$, due to the ordering of the lamellae of the P4VP(PDP) comb block oriented parallel to the surface. Thus, in the thin films of SP2, the larger $(\sim 41.3 \mathrm{~nm})$ PS-rich cylindrical microdomains are oriented normal to the surface and the smaller ( $\sim 3.7 \mathrm{~nm}) \mathrm{P} 4 \mathrm{VP}(\mathrm{PDP})$ lamellar domains are oriented parallel to the surface.

The results presented above show that lamellae-withinlamellae and cylinders-within-lamellae can be obtained using different BCPs at a fixed ratio of PDP to 4VP (1:1). Simply by adjusting the ratio of PDP to 4VP, lamellae-within-lamellae and cylinders-within-lamellae can be obtained using one PS- $b$-P4VP copolymer. PS- $b$-P4VP(PDP) constructed using PS(26200)- $b$ P4VP(12400) with different $R_{0}$ (molar ratio of PDP to P4VP) from 0.64 to 1.80 are listed as sample SP3-1, SP3-2, and SP3-3 in Table 1. Figure 6 shows a series of SPM phase images and GISAXS patterns of SP3-1, SP3-2, and SP3-3, respectively. As 

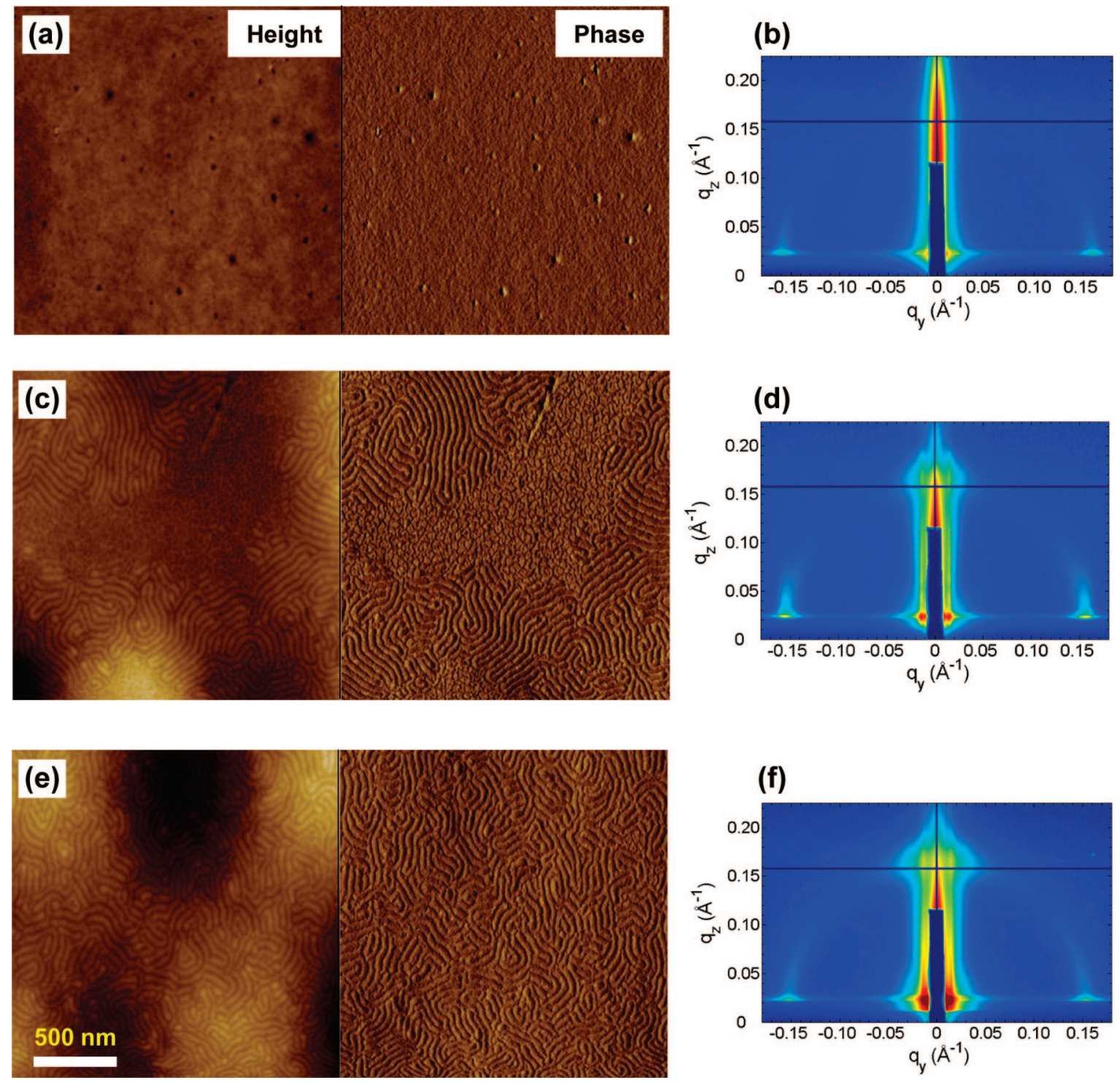

Figure 8. SFM height and phase image and GISAXS pattern of (a) and (b): a 50 nm SP5-1 thin film, showing a parallel lamellae-within-lamellae morphology; (c) and (d): a $~ 62 \mathrm{~nm}$ SP5-2 thin film, showing a mixed morphology of parallel and perpendicular lamellae-within-lamellae; (e) and (f): a $\sim 68 \mathrm{~nm}$ SP5-3 thin film, showing a perpendicular lamellae-within-lamellae morphology. The $z$ scale for height and phase is $20 \mathrm{~nm}$ and $40^{\circ}$ for (a), $30 \mathrm{~nm}$ and $50^{\circ}$ for (c), and $35 \mathrm{~nm}$ and $50^{\circ}$ for (e).

seen in Figure 6a,b, SP3-1 $\left(R_{0}=0.64, f_{\text {comb }} \sim 0.57\right)$ assembled into a lamellae-within-lamellae morphology with a macroscopic orientation similar to what was seen in SP1 thin films. As $R_{0}$ is increased to 1.8 (SP3-3, $\left.f_{\text {comb }} \sim 0.75\right)$, SP3-3 assembled into a cylinders-within-lamellae morphology, as shown in Figure 6e,f, which is similar to that seen in SP2. For SP3-2 where the PDP/ $4 \mathrm{VP}$ ratio is in between, i.e. at $R_{0}=1.27$, a coexistence of wormlike and circular microdomains is found (Figure $6 c, d$ ). Thus, by varying the amount of PDP added to the BCP-based supramolecules, different hierarchical assemblies can be accessed in thin films. In addition, the macroscopic orientation of the supramolecular assemblies at different length scales can be achieved.

For all of the PS- $b$-P4VP(PDP) supramolecules shown (SP1, $\mathrm{SP} 2$, and SP3), the $\mathrm{P} 4 \mathrm{VP}(\mathrm{PDP})$ fractions are higher than 0.55 and form oriented hierarchical structures where the BCP microdomains, tens of nanometers in size, are oriented normal to the surface and lamellar comb structures, $\sim 4 \mathrm{~nm}$ in size, are oriented parallel to the surface. As the P4VP(PDP) fraction decreases, different orientations were observed. SP4 is constructed using PS(40000)- $b$-P4VP(5600) and forms a lamellaewithin-lamellae morphology in the bulk. Figure 7 a shows the
SPM image of a $\sim 93 \mathrm{~nm} \mathrm{SP4} \mathrm{thin} \mathrm{film} \mathrm{after} \mathrm{solvent} \mathrm{annealing}$ under chloroform for $48 \mathrm{~h}$. Lamellar microdomains oriented normal to the surface were not seen, and the film surface is essentially flat. The cracklike features on the surface are $\sim 2$ $\mathrm{nm}$ in depth. As shown later, this is due to the P4VP(PDP) comb block on the surface assembling during solvent evaporation. These observations indicate that, unlike what was seen in SP1, the SP4 thin films contain BCP lamellar microdomains oriented parallel to the surface. Figure 7b shows a GISAXS pattern $\left(\alpha_{\text {in }}\right.$ $=0.2^{\circ}$ ) of the same SP4 thin film. Diffraction rods originating from the BCP lamellae microdomains oriented normal to the surface, tens of nanometers in size, are absent, which is consistent with the SPM observations. However, reflections at $q_{y}=0.152 \AA^{-1}$ can be clearly seen, confirming the lamellar comb structure of the P4VP(PDP) block is oriented normal to the surface. GISAXS studies at a lower incidence angle, $\alpha_{\text {in }}=$ $0.135^{\circ}$, confirmed the P4VP(PDP) has a lower surface tension than the PS-rich block and forms the top layer of the thin film (data not shown). Thus, in SP4 thin films, the lamellar microdomains originating from the copolymer microphase separation are oriented parallel to the surface and the lamellar comb structures from the P4VP(PDP) comb block are oriented 

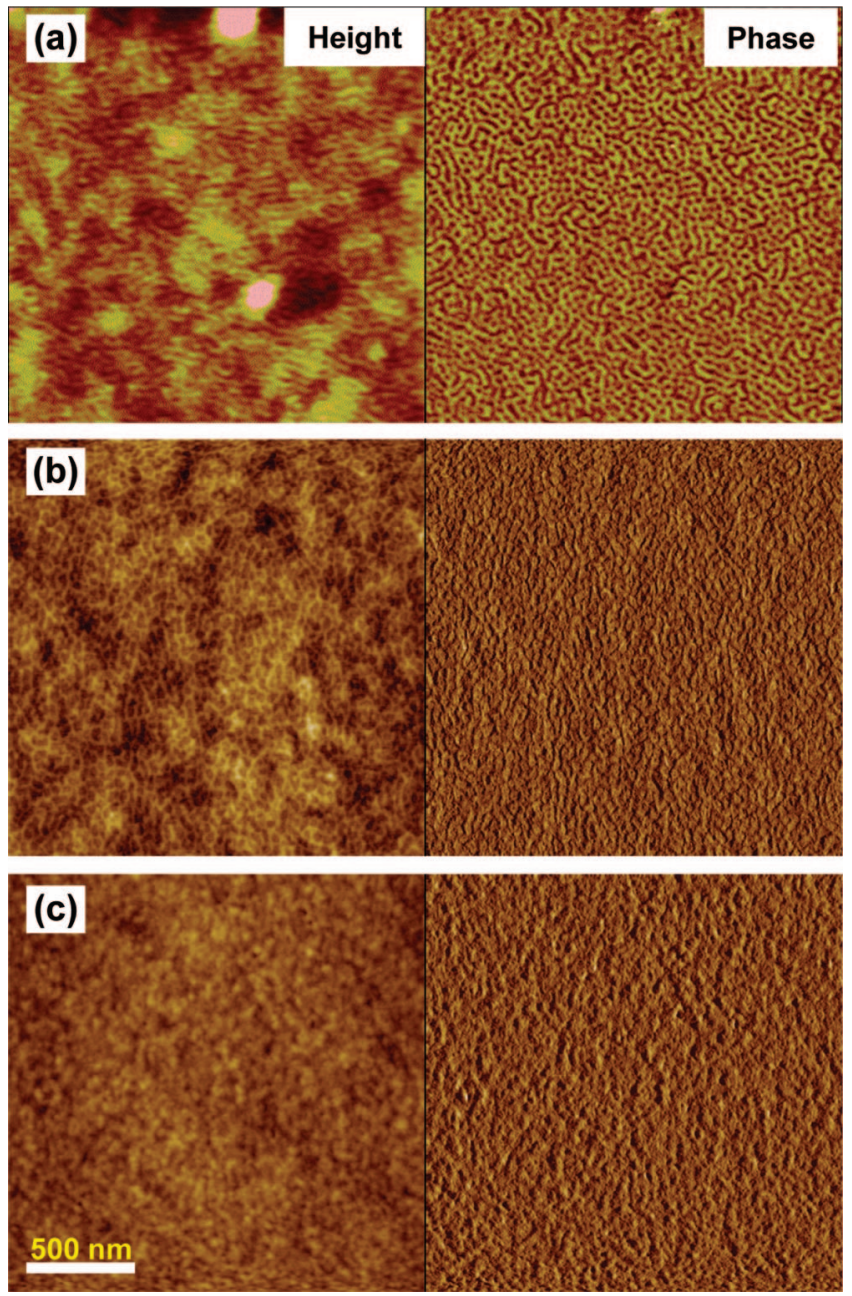

Figure 9. SPM images of (a) SP1, $\sim 88 \mathrm{~nm}$ in thickness, (b) SP2, $\sim 80$ $\mathrm{nm}$, and (c) SP4, $\sim 50 \mathrm{~nm}$, thin films after spin-casting. The $z$ scale for height and phase is $10 \mathrm{~nm}$ and $15^{\circ}$ for (a) and $15 \mathrm{~nm}$ and $65^{\circ}$ for (b) and (c).

normal to the surface. Although both SP1 and SP4 form a lamellae-within-lamellae hierarchical assembly, their thin films have preferred orientations that are rotated $90^{\circ}$ with respect to each other.

We further conducted a series of experiments to examine the dependence of the orientation of lamellae-within-lamellae hierarchical assembly on $R_{0}$ with a slightly lower P4VP fraction (SP5-1, SP5-2, and SP5-2). All three samples form lamellaewithin-lamellae structure in bulk, as listed in Table 1. For SP5-1 thin films, i.e. $R_{0}=1\left(f_{\text {comb }}=0.32\right)$, the SPM images and GISAXS indicated a lamellar morphology parallel to the surface (Figure 8a,b). As $R_{0}$ is increased to 2 (SP5-2, $\left.f_{\text {comb }}=0.45\right)$, the SPM images showed a coexistence of parallel and perpendicular lamellae (Figure 8c,d). As $R_{0}$ is further increased to 2.5 (SP5$\left.3, f_{\text {comb }}=0.50\right)$, perpendicular BCP lamellae can be seen in the SPM images and were confirmed by the GISAXS studies (Figure 8e,f). Similar results were found for films with thicknesses ranging from 45 to $110 \mathrm{~nm}$. However, as the PDP fraction increased, the degree of ordering of the comb P4VP(PDP) block reduced as seen in the GISAXS pattern in Figure 8f. For $R_{0}>$ 1 , there are a large fraction of free PDPs that are not hydrogenbonded with $4 \mathrm{VP}$, and their spatial distribution is unclear. We are carrying out systematic neutron reflectivity studies to address these questions. Nevertheless, both SPM and GISAXS studies showed that the macroscopic orientation of lamellae-withinlamellae PS- $b$-P4VP(PDP) supramolecules can be tailored by varying the PDP to $4 \mathrm{VP}$ ratios.
Figure 9 shows the SPM images of SP1, SP2, and SP4 thin films right after spin-casting. SP1 and SP2 showed the ordered microdomains, possibly, oriented normal to the surface and SP4 showed a flat surface. There is a strong correlation between the P4VP(PDP) content and the film surface topography after spincasting and, ultimately, the orientation of the hierarchical assembly of the PS- $b$-P4VP(PDP) after solvent annealing. Thus, the macroscopic orientation of PS- $b$-P4VP(PDP) depends on the synergistic coassembly of PDP and PS- $b$-P4VP on two different length scales. The P4VP(PDP) comb block assembly plays an important role and complements the orientation induced by the solvent field.

During the spin-coating process, solvent evaporation introduces a strong gradient field normal to the film surface that can be used to bias the microdomain orientation in thin films of BCPs. ${ }^{3,4,36-38}$ With subsequent solvent annealing, the solvent mediates interactions between each component and with the underlying substrate and imparts mobility to the copolymer. ${ }^{3,4,38-40}$ Thus, highly oriented arrays of nanoscopic microdomains with a high degree of long-range lateral order can be produced. In the case of BCP-based supramolecules, two assembly processes occur simultaneously on two different length scales; i.e., the BCP phase separates to form microdomains tens of nanometers in size, and the P4VP(PDP) comb blocks assemble into lamellar structures, a few nanometers in size. ${ }^{41,42}$ The synergistic interplay between these two processes during spin-coating is critical in determining the orientation of PS- $b$ P4VP(PDP) supramolecules in thin films. Results on SP4 thin films clearly show that the solvent field alone is not sufficient to orient the BCP microdomain normal to the surface in PS- $b$ P4VP(PDP) thin films. In subsequent solvent annealing, chloroform is not able to neutralize the preferrential interactions between each component of PS- $b$-P4VP(PDP) with the underlying substrate and at the surface. P4VP(PDP) has a lower surface tension that orients the $\mathrm{BCP}$ lamellae parallel to the surface. ${ }^{43-46}$ However, when the P4VP(PDP) fraction is higher than a critical value, the preferrential interactions between the supramolecules with the underlying substrate and the lower surface tension of $\mathrm{P} 4 \mathrm{VP}(\mathrm{PDP})$ can be overcome. The BCP microdomains can be oriented normal to the surface, which, in turn, provide a framework for the P4VP(PDP) comb blocks to assemble with a preferred macroscopic orientation. Thus, oriented hierarchical structures can be obtained by tailoring the P4VP(PDP) fraction without interfering with the supramolecular morphologies.

\section{Conclusions}

In conclusion, we have described the hierarchical assembly of BCP-based supramolecules in thin films. Two hierarchical structures, lamellae-within-lamellae and cylinders-within-lamellae, were observed in the supramolecular thin films. The supramolecular assemblies can be macroscopically oriented on two different length scales, i.e., $\sim 4$ and $\sim 40 \mathrm{~nm}$, simultaneously in thin films. Thus, hierarchical structures with macroscopic orientation can be achieved in BCP-based supramolecular thin films. Furthermore, the synergistic coassembly of BCP and small molecules in thin films can be used to generate oriented hierarchical structures. The macroscopic orientation of supramolecular assembly depends on the P4VP(PDP) fraction and can be tailored without interfering with the supramolecular morphologies.

The BCP-based supramolecular thin films described here offer numerous opportunities to fabricate functional devices. The microdomains can be oriented normal to the surface without surface modification. Since BCP-based supramolecules can be easily prepared by attaching small molecules to a copolymer, various built-in functionalities can be readily incorporated. The fundamental principles outlined here should be potentially 
applicable to other systems. Thin films of BCP-based supramolecules may find numerous applications in the fabrication of functional nanodevices.

Acknowledgment. We thank Thomas Schilling and Evangeline Wong for help with initial construction of supramolecules and scattering experiments. We acknowledge Dr. Alexander Hexemer and Mr. Eliot Gann at ALS for facilitating SAXS and GISAXS experiments. We thank Dr. Michael Sprung and Dr. Jin Wang at APS (Argonne, IL) for facilitating the GISAXS experiments. Use of the Advanced Photon Source was supported by the U.S. Department of Energy, Office of Science, Office of Basic Energy Sciences, under Contract DE-AC02-06CH11357. The dPS- $b$-P4VP was provided by CNMS-ORNL, sponsored by the Scientific User Facilities Division, Office of Basic Energy Sciences, U.S. Department of Energy. We thank Dr. David Uhrig, Dr. Deanna Pickel, and Dr. Jamie Messman for their assistance in polymer synthesis. This work was supported by the Short-term Innovative Research Grant from Army Research Office at Department of Defense under Contract W911NF-07-1-0653 and the University of California Energy Institute (UCEI) under Grant 023205.

Supporting Information Available: Details on the synthesis and characterization of PS(26200)- $b$-P4VP(12400), the SAXS profiles of PS- $b$-P4VP(PDP) supramolecules in bulk, SPM images from the bottom of the SP1 and SP2 films, and the optical microscopy images of SP1 thin film surface. This material is available free of charge via the Internet at http://pubs.acs.org.

\section{References and Notes}

(1) Hawker, C. J.; Russell, T. P. MRS Bull. 2005, 30, 952-966.

(2) Angelescu, D. E.; Waller, J. H.; Register, R. A.; Chaikin, P. M. Adv. Mater. 2005, 17, 1878-1881.

(3) Kim, S. H.; Misner, M. J.; Xu, T.; Kimura, M.; Russell, T. P. Adv. Mater. 2004, 16, 226-231.

(4) Kimura, M.; Misner, M. J.; Xu, T.; Kim, S. H.; Russell, T. P. Langmuir 2003, 19, 9910-9913.

(5) Segalman, R. A.; Yokoyama, H.; Kramer, E. J. Adv. Mater. 2001, 13, $1152-1155$

(6) Thurn-Albrecht, T.; Schotter, J.; Kastle, C. A.; Emley, N.; Shibauchi, T.; Krusin-Elbaum, L.; Guarini, K.; Black, C. T.; Tuominen, M. T.; Russell, T. P. Science 2000, 290, 2126-2129.

(7) Park, M.; Harrison, C.; Chaikin, P. M.; Register, R. A.; Adamson, D. Science 1997, 276, 1401.

(8) Morkved, T. L.; Lu, M.; Urbas, A. M.; Ehrichs, E. E.; Jaeger, H. M.; Mansky, P.; Russell, T. P. Science 1996, 273, 931-933.

(9) Fasolka, M. J.; Mayes, A. M. Annu. Rev. Mater. Res. 2001, 31, 323355.

(10) Knoll, A.; Horvat, A.; Lyakhova, K. S.; Krausch, G.; Sevink, G. J. A.; Zvelindovsky, A. V. Phys. Rev. Lett. 2002, 89, 035501.

(11) Melde, B. J.; Burkett, S. L.; Xu, T.; Goldbach, J. T.; Russell, T. P. Chem. Mater. 2005, 17, 4743-4749.

(12) Valkama, S.; Ruotsalainen, T.; Nykanen, A.; Laiho, A.; Kosonen, H.; ten Brinke, G.; Ikkala, O.; Ruokolainen, J. Macromolecules 2006, 39, 9327-9336.
(13) Ruokolainen, J.; Saariaho, M.; Ikkala, O.; ten Brinke, G.; Thomas, E. L.; Torkkeli, M.; Serimaa, R. Macromolecules 1999, 32, 11521158.

(14) Ikkala, O.; ten Brinke, G. Chem. Commun. 2004, 2131-2137.

(15) Osuji, C. O.; Chao, C. Y.; Ober, C. K.; Thomas, E. L. Macromolecules 2006, 39, 3114-3117.

(16) Osuji, C.; Ferreira, P. J.; Mao, G. P.; Ober, C. K.; Vander Sande, J. B.; Thomas, E. L. Macromolecules 2004, 37, 9903-9908.

(17) Bates, F. S.; Fredrickson, G. H. Аnnи. Rev. Phys. Chem. 1990, 41, 525-557.

(18) Leibler, L. Macromolecules 1980, 13, 1602-1617.

(19) Wood, K. C.; Little, S. R.; Langer, R.; Hammond, P. T. Angew. Chem., Int. Ed. 2005, 44, 6704-6708.

(20) Chao, C. Y.; Li, X. F.; Ober, C. K.; Osuji, C.; Thomas, E. L. Adv. Funct. Mater. 2004, 14, 364-370.

(21) Kosonen, H.; Ruokolainen, J.; Knaapila, M.; Torkkeli, M.; Serimaa, R.; Bras, W.; Monkman, A. P.; ten Brinke, G.; Ikkala, O. Synth. Met. 2001, 121, 1277-1278.

(22) van Ekenstein, G. A.; Polushkin, E.; Nijland, H.; Ikkala, O.; ten Brinke, G. Macromolecules 2003, 36, 3684-3688.

(23) Sidorenko, A.; Tokarev, I.; Minko, S.; Stamm, M. J. Am. Chem. Soc. 2003, 125, 12211-12216.

(24) Morikawa, Y.; Nagano, S.; Watanabe, K.; Kamata, K.; Iyoda, T.; Seki, T. Adv. Mater. 2006, 18, 883-886.

(25) Saariaho, M.; Subbotin, A.; Szleifer, I.; Ikkala, O.; ten Brinke, G. Macromolecules 1999, 32, 4439-4443.

(26) Tokarev, I.; Krenek, R.; Burkov, Y.; Schmeisser, D.; Sidorenko, A.; Minko, S.; Stamm, M. Macromolecules 2005, 38, 507-516.

(27) Laforgue, A.; Bazuin, C. G.; Prud'homme, R. E. Macromolecules 2006, 39, 6473-6482.

(28) Albrecht, K.; Mourran, A.; Zhu, X.; Markkula, T.; Groll, J.; Beginn, U.; deJeu, W. H.; Moeller, M. Macromolecules 2008, 41, 1728-1738.

(29) Chen, J. T.; Thomas, E. L.; Ober, C. K.; Mao, G. P. Science 1996, $273,343-346$.

(30) Anthamatten, M.; Hammond, P. T. J. Polym. Sci., Part B: Polym. Phys. 2001, 39, 2671-2691.

(31) Zheng, W. Y.; Hammond, P. T. Macromolecules 1998, 31, 711-721.

(32) Olsen, B. D.; Segalman, R. A. Macromolecules 2006, 39, 7078-7083.

(33) van Zoelen, W.; Asumaa, T.; Ruokolainen, J.; Ikkala, O.; ten Brinke, G. Macromolecules 2008, 41, 3199-3208.

(34) Ruokolainen, J.; ten Brinke, G.; Ikkala, O. Adv. Mater. 1999, 11, 777780.

(35) Factor, B. J.; Russell, T. P.; Toney, M. F. Macromolecules 1993, 26, 2847-2859.

(36) Lin, Z. Q.; Kim, D. H.; Wu, X. D.; Boosahda, L.; Stone, D.; LaRose, L.; Russell, T. P. Adv. Mater. 2002, 14, 1373-1376.

(37) Kim, G.; Libera, M. Macromolecules 1998, 31, 2670-2672.

(38) Kim, G.; Libera, M. Macromolecules 1998, 31, 2569-2577.

(39) Dair, B. J.; Avgeropoulos, A.; Hadjichristidis, N.; Capel, M.; Thomas, E. L. Polymer 2000, 41, 6231-6236.

(40) Albalak, R. J.; Thomas, E. L. J. Polym. Sci., Part B: Polym. Phys. 1993, 31, 37-46.

(41) van Ekenstein, G.; Meyboom, R.; ten Brinke, G.; Ikkala, O. Macromolecules 2000, 33, 3752-3756.

(42) Ruokolainen, J.; Makinen, R.; Torkkeli, M.; Makela, T.; Serimaa, R.; ten Brinke, G.; Ikkala, O. Science 1998, 280, 557-560.

(43) Xu, T.; Hawker, C. J.; Russell, T. P. Macromolecules 2005, 38, 28022805.

(44) Karim, A.; Singh, N.; Sikka, M.; Bates, F. S. J. Chem. Phys. 1994, $100,1620$.

(45) Anastasiadis, S. H.; Russell, T. P.; Satija, S. K.; Majkrzak, C. F. Phys. Rev. Lett. 1989, 62, 1852.

(46) Hasegawa, H.; Hashimoto, T. Macromolecules 1985, 18, 589-590. MA800726R 